\title{
O PAPEL DA ADVOCACIA PÚBLICA FEDERAL NA CONCEPÇÃO E IMPLEMENTAÇÃO DE POLÍTICAS PÚBLICAS
}

\author{
Dijonilson Paulo Amaral Veríssimo ${ }^{36}$
}

Recebido em: 17/11/2018

Aprovado em: 27/12/2018

\begin{abstract}
RESUMO
O estudo apresentado objetiva demonstrar a importância da atuação da advocacia pública federal, especialmente nas fases de concepção e implementação das políticas públicas. Inicialmente busca-se abordar os antecedentes históricos, composição e carreiras da Advocacia-Geral da União. Após, procura-se analisar as atribuições constitucionais e legais da instituição e sua posição na Constituição Federal de 1988 como função essencial à justiça. Adota-se a metodologia dedutiva, buscando elementos na legislação, jurisprudência e doutrina, com análise crítico-construtiva.
\end{abstract}

Palavras-chave: Advocacia Pública Federal. Função essencial à justiça. Histórico. Composição e atribuições. Atuação na concepção e implementação de políticas públicas.

\section{INTRODUÇÃO}

Atualmente, no âmbito de um Estado Democrático de Direito, a implementação de políticas públicas necessariamente depende de sua adequação ou inserção ao ordenamento jurídico, ao sistema de regras e princípios que norteiam a atividade estatal e a sociedade brasileira. Sem dúvida, em razão de sua missão institucional prevista na Constituição Federal, a Advocacia Pública tornou-se uma peça chave para a efetiva implementação de políticas públicas.

Nesse contexto, percebe-se que a Advocacia Pública vem, nos últimos anos, assumindo um relevante papel para viabilizar e assegurar a implementação de políticas públicas nas três esferas de governo, sem a qual os objetivos pretendidos pelos gestores não

\footnotetext{
${ }^{36}$ Mestrando em Direito pela Universidade Federal do Rio Grande do Norte - UFRN. Especialista em Direito Público pela UFRN. Especialista em Direito Tributário pela Universidade Anhanguera-Uniderp. Especialista em Direito Previdenciário pela Universidade Anhanguera-Uniderp.
} 
seriam alcançados. Esse momento preventivo, administrativo, no seio dos órgãos integrantes do Executivo e Legislativo é de extrema importância.

De igual forma, observa-se um crescente controle do Poder Judiciário sobre as políticas públicas, interferido no conteúdo das escolhas políticas idealizadas pela maioria governante. O Judiciário passa a assumir a corresponsabilidade na efetivação das metas e compromissos estatais, interferindo de maneira mais incisiva no controle do processo político. E, nesse ponto, a atuação da Advocacia Pública torna-se necessária e indispensável para a defesa do interesse público no modelo idealizado pelos representantes da sociedade.

Inevitavelmente, o Judiciário começou a ser demandado a decidir sobre a compatibilidade dos atos comissivos e omissivos das demais formas de expressão do poder estatal para a concreção desses direitos sociais, de forma que, a partir do momento em que passou a exercer o controle de constitucionalidade das ações do Estado, tornou-se um ator fundamental para a efetivação das políticas públicas.

Observa-se que o Judiciário não está como protagonista para, sozinho, restabelecer o equilíbrio entre os Poderes, verificando a necessidade de trazer para o debate jurídico-político a advocacia pública, especialmente por ter a função de controlar a juridicidade das escolhas emanadas pelo Poder Executivo.

O presente artigo propõe inicialmente expor um breve histórico legislativo da Advocacia Pública federal, especialmente quando encartada pela Constituição Federal de 1988 (CRFB/88) como função essencial à Justiça. Posteriormente, apresentar-se-á um panorama das carreiras e atribuições constitucionais e legais da Advocacia-Geral da União (AGU). Por fim, abordar-se-á a atuação da advocacia pública federal nas fases de concepção e implementação das políticas públicas da União, mormente no atual período de intensa judicialização dessas políticas.

Quanto à metodologia adotada, pretende-se aplicar a metodologia dedutiva, partindose de conhecimentos gerais para o específico, com a abordagem do tema proposto sob a ótica das técnicas das pesquisas bibliográfica e documental, buscando elementos na legislação pertinente à matéria, na doutrina nacional e estrangeira e na jurisprudência pátria. A partir desse levantamento, procede-se à análise crítico-construtiva do material para apresentação de conclusões viáveis à solução da problemática apresentada.

\section{A ADVOCACIA-GERAL DA UNIÃO: ANTECEDENTES HISTÓRICOS, CARREIRAS E ATRIBUIÇÕES}


A advocacia pública federal tem seu surgimento desde o período imperial. Todavia, é no período republicano que pode se notar uma maior semelhança institucional com o que atualmente se verifica. De acordo com GUEDES e HAUSHILD (2009, p. 09), o cargo de Desembargador Procurador dos Feitos da Coroa e Fazenda é outro exemplo de antecedentes de advogado de Estado. Ele consta no Regimento de 7 de março de 1609, que instala a Relação do Estado do Brasil, na capital Salvador e no Regimento que determina sua reinstalação em 1962.

O professor José Afonso da Silva relata de forma estrutural a situação histórica da Advocacia Pública, presente desde o surgimento do Estado:

\begin{abstract}
Esse relevo, a essencialidade e indispensabilidade da Advocacia pública, desde sempre, revela ser ínsita à estrutura do Estado. Quando este era Estado mínimo, a presença da Advocacia Pública era mais modesta, mas nem por isso ausente, como prova o nosso sistema constitucional. Assim, no Império, era o Ministério Público que cumpria essa função. Anota Pimenta Bueno, o 'governo tem o dever e necessidade de defender perante os tribunais a propriedade e manutenção dos direitos da coroa ou nacionais', e essa defesa incumbia ao Ministério Público, mas o Procurador da coroa é que exercia essa função perante os Tribunais Superiores. Era o Ministério Público exercendo a dupla função de promoção da ação penal e de defesa dos interesses do Estado. Igual sistema perdurou no regime da Constituição de 1891, segundo o qual o Presidente da República designaria, dentre os membros do Supremo Tribunal Federal, o Procurador-Geral da República, cujas atribuições se definiram em lei, e esta conferia à Procuradoria Geral da República aquela dupla função. Foi a Constituição de 1934 que institucionalizou a Advocacia Pública da União, embora com a denominação de Ministério Público, como um dos órgãos de cooperação nas atividades governamentais (arts. 95-98). E aí também já se acenava para a instituição no âmbito dos Estados (art. 97). Essa institucionalização perdurou nas Constituições de 1946, num título autônomo (Tít. III), e perdurou nas Constituições de 1967 e 1969, naquela no título do Poder Judiciário e nesta no título do Poder Executivo, e nelas com referência explícita ao ministério Público dos Estados, que nestes tomou um sentido diferente do Ministério Público Federal. (SILVA, 2002, p. 282)
\end{abstract}

A representação judicial da União e de suas autarquias e fundações públicas federais foi atribuída ao Ministério Público Federal. No final do ano de 1938 e início do ano de 1939, o Decreto-lei ${ }^{\circ}$ 986, de 27 de dezembro de 1938 e o Decreto-lei $n^{\circ} 1.215$, de 24 de abril de 1939 confiaram ao Ministério Público Federal a representação judicial da União e de suas Autarquias.

Em 1946, a Constituição estabeleceu que a União seria representada em Juízo pelos Procuradores da República, podendo a lei cometer esse encargo, nas Comarcas do interior, ao Ministério Público local. 
No ano de 1951, a Lei Federal $n^{\circ} 1.341$, de 30 de janeiro, veiculou a primeira Lei Orgânica do Ministério Público da União, na qual novamente constaram as atribuições de representação judicial da União, da Fazenda Nacional e das Autarquias federais.

A Constituição de 1967 reiterou a disposição, já prevista na Constituição de 1946, de que a União seria representada em Juízo pelos Procuradores da República, com a possibilidade de a lei cometer esse encargo, nas Comarcas do interior, ao Ministério Público local.

A CRFB/88 separou as funções de Ministério Público e de Advocacia Pública, tendo confiado à Advocacia-Geral da União a representação judicial e extrajudicial da União, tanto de suas atividades centralizadas na administração direta quanto das descentralizadas nas autarquias e fundações públicas federais, e a consultoria jurídica do Poder Executivo, igualmente tanto da administração direta quanto da indireta autárquica e fundacional.

Com o advento da atual Constituição, o conglomerado das carreiras jurídicas do Serviço Jurídico da União e de órgãos da Advocacia Consultiva da União (exceto os órgãos jurídicos das empresas públicas, sociedades de economia mista, e demais entidades controladas, direta ou indiretamente, pela União), foi abrigado pela Advocacia-Geral da União, à qual foi confiada a representação, judicial e extrajudicial, da União, podendo exercêlas diretamente ou através de órgão vinculado, e as atividades de consultoria e assessoramento jurídico do Poder Executivo.

O que se verifica, dentro essa evolução histórica, é que a Constituição de 1988 optou por separar as funções de Ministério Público e de Advocacia Pública, bem como estabeleceu que a representação judicial e extrajudicial da União, bem como a consultoria e assessoramento do Poder Executivo, seria feita pela nova instituição intitulada AdvocaciaGeral da União.

Note-se que o constituinte deixou claro que, seja diretamente ou através de órgão vinculado, é a instituição Advocacia-Geral da União que tem o papel de representar judicial e extrajudicialmente a União e exercer as atividades consultoria e assessoramento jurídico do Poder Executivo.

A criação da Advocacia-Geral da União pela Constituição de 1988 trouxe importantes mudanças à organização do serviço jurídico da União. A instituição foi incumbida de representar judicial e extrajudicialmente a União, competindo-lhe ainda prestar consultoria e assessoramento jurídico ao Poder Executivo - atividades que, até a promulgação da vigente Carta Política, eram desempenhadas pelo Ministério Público da União e pela ConsultoriaGeral da República, respectivamente. 
No modelo constitucional vigente, a Advocacia Pública, disciplinada na Seção II, Capítulo IV, Título IV da CRFB/1988, foi confiada, no âmbito federal, exclusivamente à AGU. Nos termos do art. 131 da Constituição, o desempenho dessa atribuição pode ser realizado diretamente pela AGU ou por meio de órgão que lhe seja vinculado, observada a lei complementar que dispõe sobre sua organização e funcionamento.

De modo a assegurar a harmonia da transição do antigo regime constitucional para o novo, o poder constituinte originário definiu as atividades jurídicas que compõem o conceito de Advocacia Pública, tratado na Seção II, Capítulo IV, Título IV da CRFB/88, estabelecendo regras de caráter meramente transitório no art. 29 do Ato das Disposições Constitucionais Transitórias.

Da análise do texto constitucional, a representação judicial e extrajudicial, bem como a consultoria e o assessoramento jurídico das autarquias e fundações públicas federais, receberam tratamento de atividades típicas da advocacia pública. Tais atividades, por força do art. 131 da $\mathrm{CRFB} / 88$, podem ser exercidas diretamente pela $\mathrm{AGU}$ ou por meio de órgão vinculado, conforme definido em lei complementar.

Ao estruturar a AGU, a Lei Complementar no 73/1993 definiu os órgãos de direção superior, de execução e de assistência direta ao Advogado-Geral da União, conferindo às Procuradorias, Departamentos, Consultorias e Assessorias Jurídicas das autarquias e fundações públicas federais, na qualidade de órgãos a ela vinculados, a representação judicial e extrajudicial destas entidades, bem como o exercício das respectivas atividades de consultoria e assessoramento jurídicos.

Com a edição da Lei Complementar no 73/1993, cria-se a Procuradoria da União e a Procuradoria da Fazenda Nacional e, com a Lei n ${ }^{\circ}$ 10.480/2002, a Procuradoria-Geral Federal e a carreira de Procurador Federal. Além dessas, há a Procuradoria-Geral do Banco Central do Brasil, criada pela Lei $n^{\circ} 9.650 / 1998$.

Dessa forma, as quatro carreiras são materialmente consideradas parte da AdvocaciaGeral da União, com o seguinte desenho de atribuições: a) Advogado da União - função consultiva e contenciosa da Administração Direta, exceto em causas tributárias da competência da Procuradoria-Geral da Fazenda Nacional; b) Procurador Federal representação judicial, extrajudicial, a consultoria e assessoramento jurídicos de autarquias e fundações públicas federais; c) Procurador da Fazenda Nacional - função consultiva e contenciosa da Administração Direta em causas de natureza fiscal; d) Procurador do Banco Central - função consultiva e contenciosa do Banco Central do Brasil. 


\section{ADVOCACIA PÚBLICA ${ }^{37}$ COMO FUNÇÃO ESSENCIAL À JUSTIÇA}

O capítulo referente às Funções Essenciais à Justiça encontra-se dentro do Título IV, Da Organização dos Poderes. Essa sistematização foi observada para atender os preceitos modernos do Estado Democrático de Direito.

Ao descrever sua teoria sobre a tripartição dos poderes, MONTESQUIEU (1996) já alertava sobre a possibilidade de, em algum momento, haver prevalência de um Poder em relação aos demais. A forma de manter a harmonia entre os mesmos seria por meio dos freios e contrapesos. Há, pois, necessidade adaptá-la ao surgimento do Estado Democrático de Direito, vez que teve como parâmetro o absolutismo europeu.

Assim, o Poder Constituinte Originário inseriu, no art. $2^{\circ}$ da Constituição Federal de 1988, entre os princípios fundamentais da República Federativa do Brasil, a separação orgânica das funções estatais ${ }^{38}$, considerada cláusula pétrea, ante o que preceitua o art. 60, $\S 4^{\circ}$, III, da CF/88.

No Capítulo "Das Funções Essenciais à Justiça", o constituinte originário incluiu instituições e órgãos que possuem algumas atribuições, dentre as quais: de defender a sociedade, o Estado, os hipossuficientes e o cidadão, dentro de um mesmo patamar hierárquico.

Dessa forma, no cenário político após a Constituição de 1988, o equilíbrio e a harmonia entre os Poderes, dentro de uma perspectiva do Estado Democrático de Direito, são concretizados, em parte, por meio das Funções Essenciais à Justiça.

Por outro lado, a referência a "Justiça" não teve um alcance restrito, de prestação jurisdicional, mas sim de imparcialidade, isonomia, preservação dos direitos, restrição à ingerência estatal, cidadania e democracia, o que MOREIRA NETO (1991, p. 13) convencionou chamar de "Estado de Justiça".

Nessa perspectiva, o Poder Judiciário não seria o único responsável pela prestação da Justiça, necessitando da intervenção do Ministério Público, da Advocacia Pública, da Defensoria Pública e da Advocacia Privada, como garantidores e defensores dos interesses da sociedade e do Estado.

\footnotetext{
${ }^{37}$ A nomenclatura "Da Advocacia Pública" foi inserida na Seção II, do Capítulo IV, por meio da EC no 19/1998, abrangendo tanto a Advocacia-Geral da União quanto as Procuradorias dos Estados e do Distrito Federal. Anteriormente a referência era restrita: "Da Advocacia-Geral da União"

38 Remete-se à expressão "separação orgânica das funções estatais", o que coloquialmente se denomina "tripartição dos poderes".
} 
Mais a mais, pode-se acrescer, ainda segundo as lições de Diogo de Figueiredo Moreira Neto:

\begin{abstract}
Não haja dúvida de que, ao recolher, na evolução teórica e prática do constitucionalismo dos povos cultos, novíssimas expressões institucionais, como o são a participação política e as funções essenciais à justiça, o Constituinte de 1988 deu um passo definitivo e, oxalá, irreversível, para a preparação do Estado brasileiro do segundo milênio como um Estado de Justiça, aspiração, como se expôs, mais ambiciosa do que a realização de um Estado Democrático de Direito, que naquela se contém e com ela se supera. (MOREIRA NETO, 1991, p. 13)
\end{abstract}

Com efeito, pode-se inferir que a positivação do Ministério Público ao lado das novas instituições Constitucionais, Advocacia Pública, Defensoria Pública e Advocacia stricto sensu veio concretizar a intenção de justaposição dessas funções, necessitando-se garantir a elas atuação dentro do mesmo patamar hierárquico e repelindo-se qualquer grau de subordinação, tendo em vista sua "essencialidade".

Em que pese não existir na realidade fática, para que haja prestação jurisdicional célere e universal, respeito ao Estado Democrático de Direito, resguardando-se os direitos e garantias fundamentais, é necessário que os atores do processo judicial possuam igualdade, tanto de prerrogativas, quanto estruturais. A Defensoria Pública, por exemplo, teve assegurada sua autonomia funcional e administrativa por meio das Emendas Constitucionais n ${ }^{\circ}$ s 45/2004 e 74/2013, sendo a primeira relativa às estaduais e a segunda da União e do Distrito Federal.

Mesma sorte não teve a Advocacia Pública, cuja autonomia funcional e prerrogativas aos seus membros ainda está pendente de apreciação pelo Legislativo em trâmite no Congresso Nacional. A Proposta de Emenda à Constituição $n^{\circ}$ 87/2007 pretende corrigir desequilíbrio constitucional, equalizando o tratamento institucional dispensado às Funções Essenciais à Justiça, uma vez que o Ministério Público, a Magistratura e a Defensoria Pública já possuem essa autonomia administrativa.

Conforme assentado pela Procuradora Federal Maria Jovita, em seu estudo sobre a história e evolução da Advocacia-Geral da União:

A Constituição de 1988, no seu Título IV, dispôs sobre a ORGANIZAÇÃO DOS PODERES e, sob esse Título, destinou o Capítulo I ao PODER LEGISLATIVO, o Capítulo II ao PODER EXECUTIVO, o Capítulo III ao PODER JUDICIÁRIO e o Capítulo IV às FUNÇÕES ESSENCIAIS À JUSTIÇA, inserindo neste último Capítulo o MINISTÉRIO PÚBLICO, na Seção I, e a ADVOCACIA PÚBLICA, na qual se inclui a ADVOCACIA-GERAL DE UNIÃO, na Seção II. Teve o Constituinte o cuidado de situar a Advocacia-Geral da União fora dos três Poderes da República, não para que formasse um "quarto poder", mas para que pudesse atender, com independência, aos três Poderes, tendo presente que a representação judicial da União - função essencial à Justiça -, confiada à nova Instituição, envolveria os três Poderes da República. Também deixou claro que a AdvocaciaGeral da União ficaria responsável pelas atividades de consultoria e assessoramento 
jurídicos apenas do Poder Executivo. Portanto, o laço mais forte a unir a AdvocaciaGeral da União ao Poder Executivo decorre desses serviços que lhe presta, com exclusividade. A Advocacia-Geral da União nasceu da necessidade de organizar em Instituição única a representação judicial e extrajudicial da União e as atividades de consultoria e assessoramento jurídicos do Poder Executivo, propiciando ao Ministério Público o pleno exercício de sua função essencial de "defesa da ordem jurídica - essencial à Justiça -, do regime democrático, dos interesses sociais e dos interesses individuais indisponíveis", desvencilhando-o da representação judicial da União, por vezes incompatível com os seus outros misteres. (VALENTE, 2013)

Importante salientar que as atribuições da Advocacia-Geral da União, embora frequentemente associadas ao Poder Executivo Federal, a ele não se limitam, porquanto, abrange a todos os Poderes Federados (Executivo, Legislativo, Judiciário), incluindo o Ministério Público. Daí significando sua relevância como Função Essencial à Justiça, corroborada, pela previsão constitucional do papel de curadoria da legalidade em todos os processos objetivos de controle de constitucionalidade, na forma do artigo $103, \S 3^{\circ}$, da Constituição da República, motivo pelo qual suas incumbências chegam a extrapolar até mesmo a instância política federal, mormente pelo seu dever institucional de defender a constitucionalidade de lei ou ato normativo estadual quando em contraponto com a Constituição Federal.

No que atine à atuação judicial e extrajudicial, verifica-se que o papel da AGU transcende a moldura do Poder Executivo, que é ela responsável pela representação da União como um todo, não importando a origem orgânica do ato ou interesse cuja tutela é instada a empreender.

Nesse ponto, imperioso ressaltar que a evolução jurisprudencial e a interpretação da função da AGU como garantidora do interesse público mitigaram esse conceito. Atualmente, o Advogado-Geral da União pode deixar de defender a constitucionalidade do ato quando houver manifestação anterior, em sentido contrário, do Supremo Tribunal Federal, conforme precedente na ADI 1.616/PE:

EMENTA: [...] ADVOGADO-GERAL DA UNIÃO. DEFESA DO ATO IMPUGNADO DE QUE EXISTEM PRECEDENTES DO STF. POSSIBILIDADE. $[\ldots]$

4. O munus a que se refere o imperativo constitucional (CF, artigo 103, $\S 3^{\circ}$ ) deve ser entendido com temperamentos. O Advogado- Geral da União não está obrigado a defender tese jurídica se sobre ela esta Corte já fixou entendimento pela sua inconstitucionalidade. Ação julgada procedente para declarar inconstitucional a Resolução Administrativa do Tribunal Regional do Trabalho da $6^{\mathrm{a}}$ Região, tomada na Sessão Administrativa de 30 de abril de 1997. (STF, ADI 1616, Rel. Min. Maurício Corrêa, Tribunal Pleno, julgado em 24/05/2001, DJ 24/08/2001) (grifos acrescidos)

Sempre evoluindo no papel destinado à Advocacia Pública Federal, o Advogado-Geral da União manifestou-se pela inconstitucionalidade da norma, tendo em vista a usurpação de 
competência para legislar da União. O fato ocorreu na manifestação da ADI n 4.249/SP, que versa sobre a inconstitucionalidade da Lei $n^{\circ}$ 13.521/09 do estado de São Paulo, que proibiu o consumo de cigarro em áreas coletivas, usurpando a competência da União para editar normas gerais advindas da competência concorrente para legislar sobre saúde, art. 24 , XIII e $\S \S 2^{\circ}$ e $4^{\mathrm{o}}$, da $\mathrm{CF} / 88$.

A questão sobre a possibilidade de o Advogado-Geral da União manifestar-se pela inconstitucionalidade da norma foi reanalisada e admitida pela Corte Constitucional, conforme questão de ordem no julgamento da ADI no 3.916/DF, Rel. Min. Eros Grau, Tribunal Pleno, julgado em 03/02/2010, DJe 13/05/2010.

Como adiante será abordado, a atuação da Advocacia-Geral da União na fase do planejamento, da formação e da execução da política pública propiciará planejamento estratégico do Estado, bem como a redução de demandas. Isso porque a atuação da AGU deve transcender a defesa míope da União, ajudando a atender as atribuições que o Estado moderno requer, precipuamente a viabilização das políticas públicas em favor da sociedade, o que, em última análise, importa em resguardar o interesse público, consubstanciado pela defesa do bem comum.

Queda-se, portanto, necessário dotar o Estado de condições mínimas para efetivar as atribuições constitucionalmente descritas, cabendo à AGU exercer papel estratégico na defesa do patrimônio público, dos interesses dos cidadãos e da Justiça.

Para a concretização dessas atribuições, torna-se necessária a garantia de uma Advocacia Pública independente. Isso não quer dizer que a escolha da política a ser executada deixará de ser feita pelo representante do povo, legitimamente eleito, o qual tem o direito de indicar sua equipe de governo. Todavia, a atuação de um profissional técnico, imparcial e altamente qualificado, não sujeito às pressões políticas, trará ganho de qualidade para o desenvolvimento e a execução da política pública escolhida.

Essa interpretação decorre de um processo de reflexão sobre o papel constitucional atribuído à AGU e tem contribuído para o amadurecimento das atribuições institucionais de um órgão recente na história do nosso país.

Hoje visualizamos com mais clareza o papel Constitucional destinado à AGU, de defesa do Estado sem descurar da defesa do cidadão e da sociedade. A defesa do patrimônio público, interesse público secundário, não pode se contrapor arbitrariamente aos legítimos interesses da sociedade, interesse público primário, cabendo aos membros da instituição buscar a resolução do conflito dentro do que determinam a Constituição e as leis. 
Esse controle decorre do dever mediato de defesa da Justiça, insculpido quando o Legislador Constituinte inseriu a AGU em um capítulo à parte do Poder Executivo, Função Essencial à Justiça, havendo uma imbricação de justaposição, ou melhor, necessidade de defesa do Estado desde que a ação não transborde os preceitos constitucionais e legais.

O controle de legalidade do ato administrativo poderá ser feito preventivamente ou posteriormente. Esse controle decorre da necessidade de observância ao Estado Democrático de Direito, e caberá à Advocacia-Geral da União, por meio da consultoria e assessoramento jurídicos, resguardar a constitucionalidade e a legalidade dos atos administrativos.

Essa função advém do alcance que o Legislador Constituinte atribuiu à AGU de Função Essencial à Justiça, preservando a democracia.

A respeito da temática, SILVA (2002, p. 289) demonstra a importância da Advocacia Pública no Estado Democrático de Direito consignando que só isso já demonstra quão extensa e importante é a tarefa da Advocacia Pública no Estado Democrático de Direito. Acresça-se a isso sua responsabilidade pela plena defesa dos direitos fundamentais da pessoa humana, e então se tem que seus membros saíram da mera condição de servidores públicos burocráticos, preocupados apenas com o exercício formal da atividade administrativa de defesa dos interesses patrimoniais da Fazenda Pública para se tornarem peças relevantes da plena configuração desse tido de Estado.

Assim, o papel constitucional da Advocacia Pública Federal restará bem desempenhado quando empreender todos os esforços para a proteção dos interesses do ente representado, possibilitando ao gestor executar o que fora planejado que, em última análise, são escolhas democráticas constitucionais.

\section{A ATuAÇÃo da AdVocacia pública nas FASES de CONCEPÇÃo E IMPLEMENTAÇÃO DAS POLÍTICAS PÚBLICAS DA UNIÃO}

Adentrando no tema proposto, a atuação da Advocacia Pública Federal na defesa das normas, atos e políticas da União, atualmente caracteriza-se não mais como uma simples peça fazendária encartada no processo judicial, de atuação proforma, como defensora intransigente do erário, mas sim como asseguradora de direitos amparados pela Carta Política. Essa visão está sendo percebida pelos demais atores do processo, especialmente o Judiciário.

Como é cediço, as políticas públicas de Estado são concebidas, discutidas, decidias e implantadas nesse contexto, que se consubstancia em um ambiente intranquilo e contestador, 
próprio de sociedades fundadas num pluralismo políticos (pluralidade de ideologias) e, portanto, democrático. Surge a concepção de que o interesse público é a base para a formação das políticas públicas.

Ingressando especificamente na temática "políticas públicas", analisar-se-á as fases que antecedem a sua materialização. Segundo Luiz Pedone, o processo de formação e de execução de um plano político alberga cinco etapas, a saber: $1^{\mathrm{a}}$ ) formação de assuntos públicos e de políticas públicas; $2^{\mathrm{a}}$ ) formulação de políticas públicas; $3^{\mathrm{a}}$ ) processo decisório; $4^{\mathrm{a}}$ ) implementação das políticas e $5^{\mathrm{a}}$ ) avaliação de políticas:

a) Formação de Assuntos Públicos e de Políticas Públicas - momento em que as questões públicas surgem e formam correntes de opinião ao seu redor. Isto contribui para a formação da agenda política, composta de questões que merecem políticas definidas.

b) Formulação de Políticas Públicas - processo de elaboração de políticas no Executivo, no Legislativo e em outras instituições públicas, sob os pontos de vista da racionalidade econômica, da racionalidade político-sistêmica ou da formulação responsável.

c) Processo Decisório - interligado com o anterior porém com delimitações próprias, onde atuam os grupos de pressão exercendo influência sobre os decisores, em qualquer das instâncias citadas.

d) Implementação das Políticas - processo de execução das políticas resultantes dos processos de formulação e decisão em políticas públicas, interrelacionando as políticas, os programas, as administrações públicas e os grupos sociais envolvidos ou que sofrem a ação governamental ou os problemas sociais.

e) Avaliação de Políticas — aqui consideram-se quais os padrões distributivos das políticas resultantes, isto é, quem recebe o que, quando e como, e que diferença fez com relação à situação anterior à implementação. Analisam-se os efeitos pretendidos e as conseqüências indesejáveis, bem como quais os impactos mais gerais na sociedade, na economia e na política. (PEDONE, 1986. p. 11-12)

Com espeque nas etapas indicadas pelo professor Luiz Pedone, César do Vale Kirsch infere que o papel da Advocacia Pública se destaca especialmente nas fases que compreendem a formulação das políticas públicas e a sua implementação:

Na fase de formulação de políticas públicas é que se dá, efetivamente, o início das análises, estudos e debates dos pontos e fatores existentes acerca do problema existente. Os aspectos sociais, econômicos, políticos e jurídicos são aqui discutidos, a fim de se encontrar as melhores diretrizes e coordenadas, para a resolução da questão enfrentada. Valores, princípios e leis são examinados nessa fase. Igualdade, liberdade, legalidade, moralidade, solidariedade e democracia são fatores que devem ser incorporados ao processo de discussão. A tomada de decisões é o momento em que o responsável pela política pública faz a escolha, dentre as opções que lhe foram apresentadas, para bem atingir o objetivo público colimado. O processo decisório é o momento crítico do processo de política pública, pois o governante tem de ter muita prudência e equilíbrio, para encontrar a solução mais adequada para o problema proposto. Uma decisão bem tomada terá condições de resolver o problema a ser enfrentado, ao passo que a decisão equivocadamente adotada, além de não resolver a situação, pode contribuir para agravá-la. A implementação de políticas é a execução da política pública. Ocorre quando a política já está contida necessariamente numa espécie normativa. [...] Por fim, a avaliação de políticas públicas compreende a análise dos resultados da política 
executada. Preocupa-se em saber se o programa da política pública alcançou o objetivo pretendido. A avaliação de resultados tem grande importância, pois serve para subsidiar o tomador de decisões a encontrar o caminho mais adequado, quando diante de situação que guarda semelhança com outra já previamente resolvida ou fracassada, ajudando-o a entender os motivos do sucesso ou insucesso anteriores, evitando que o mal se repita, ou aperfeiçoando o êxito alcançado. (PEDONE apud KIRCH, 2003) (grifos acrescidos)

De acordo com LIMA (2013), na medida em que o judiciário passa a intervir com mais intensidade nas políticas desenhadas pelos Poderes Executivo e Legislativo, dependendo, inclusive, do interesse dos atores políticos em acionar a via judicial, necessário se faz a análise do papel a ser desempenhado pela Advocacia Pública.

Como bem observa Tiago Cury sobre o papel da Advocacia Pública nesse contexto prévio e pós-judicialização da política idealizada pelos poderes Legislativo e Executivo:

\begin{abstract}
Ao legislador cabe criar as leis necessárias para, conferindo densidade aos comandos constitucionais, efetivar, harmoniosamente, os inúmeros interesses que representam os fins do Estado; ao administrador cabe dar fiel execução a essas leis. Num e noutro caso, escolhas serão feitas. Se à Advocacia de Estado é atribuída a função e controlar a juridicidade dessas escolhas, quando emanadas do Poder Executivo, propõe-se que tal controle consista no adequado delineamento dos limites traçados pela moldura de possibilidades de aplicação do Direito. Cabe orientar o administrador sobre como é possível agir para que ele eleja, dentre as possibilidades abertas, aquela que, segundo a vontade do povo que ele representa, melhor atenda ao desempenho do múnus que lhe cabe enquanto agente político democraticamente eleito para fazer tais escolhas. Noutras palavras, ao exercer o controle de juridicidade, deve o advogado público postar-se como autêntico cientista do Direito. Posto um problema, deverá verificar, a partir da análise do Direito a aplicar, o delineamento da moldura de possibilidades, apresentando ao agente político os limites de liberdade que a juridicidade confere a seu agir político. (CURY, 2017)
\end{abstract}

E conclui CURY (2017) que o atuar científico, orientado ao agir político, coloca da Advocacia de Estado em posição única dentre as carreiras públicas que integram as Funções Essenciais à Justiça. Dentre todas, é a única da qual pode exigir-se tal postura; as demais carreiras exercem, antes, funções jurídico-políticas, pois trazem ao Tribunal uma interpretação que pretendem seja reconhecida como a única correta para o Direito a aplicar. Dessa forma, sintetiza que ao Advogado de Estado, no papel de controle de juridicidade, cabe a função jurídico-científica, deixando ao administrador o papel decisório, o papel de política jurídica (ou, melhor, política dentro da juridicidade).

Nesse ponto, importante compreender a distinção entre função jurídico-científica e a função jurídico-política, nos moldes propostos por Hans Kelsen. À primeira, cabe estabelecer as possíveis significações de uma norma jurídica. Não há espaço para toma de decisões entre as possibilidades reveladas, devendo deixar tal decisão ao órgão que, segundo a ordem jurídica, é competente para aplicar o Direito. Essa função seria exercida pela Advocacia 
Pública para fins de orientação jurídica do poder político, exercendo o controle de juridicidade.

Noutro vértice, a decisão pela adoção de uma dentre as várias possibilidades de aplicação do Direito caberia a função jurídico-política. Para KELSEN (1999), um advogado que, no interesse do seu constituinte, propõe ao tribunal apenas uma das várias interpretações possíveis da norma jurídica a aplicar a certo caso, e um escritor que, num comentário, elege uma interpretação determinada, de entre as várias interpretações possíveis, como a única “acertada", não realizam uma função jurídico-científica, mas uma função jurídico-política (de política jurídica).

No Direito Administrativo, a discricionariedade da Administração Pública reflete o fato de que as decisões administrativas, em que pese sejam condicionadas juridicamente, são, na maioria dos casos, decisões políticas, e não jurídicas, vez que a administração é uma organização do sistema político, e não do sistema jurídico.

Quando se explana a questão da implementação das políticas públicas, significa contribuir para a formação e a execução das decisões políticas que vinculam a coletividade. Decisões essas, na maioria dos casos, discricionárias, com consequências futuras que implicam escolhas entre alternativas diversas, implicando avaliação de critérios técnicos, políticos, econômicos e jurídicos existentes.

Abordando a consultoria jurídica como atividade de "tradução", e considerando que seu objetivo é dar sustentação jurídica às políticas públicas formuladas, GUIMARÃES (2012, p. 26) sintetiza essa importante função da Advocacia Pública afirmando que o principal objetivo dessa tradução é dar sustentação jurídico-constitucional às políticas públicas formuladas e implementadas pelo Estado, como forma de garantir eficiência e legitimidade. Legitimidade no sentido de conferir transparência e publicidade aos critérios jurídicos que orientam as decisões político-administrativas, facilitando, assim, as atividades dos órgãos institucionais de controle e o próprio controle social realizada pela sociedade civil organizada. E eficiência no sentido de contribuir para a obtenção dos objetivos dessas políticas, isto é, a promoção dos direitos fundamentais do cidadão, prevenindo o quanto possível os riscos de conflito com os órgãos de controle e a eventual (e sempre prejudicial) anulação das decisões estatais.

Sobre o objetivo e importância da atividade de consultoria jurídica, consigna GUIMARÃES (2012, p. 28) que é dar consistência jurídica às decisões políticas (no sentido de discricionárias) da administração pública. A responsabilidade pela decisão, no entanto, cabe àquele que deve adotá-la, ao decisor, isto é, ao administrador. Aos órgãos de consultoria 
jurídica cabe apenas assessorá-lo, traduzindo-lhe o "direito vigente" em relação às alternativas decisórias disponíveis e às possíveis consequências jurídicas das suas decisões.

Portando, é o advogado público quem deve proporcionar a justificativa jurídica à política pública idealizada pelos poderes Legislativo e Executivo, prevenindo um possível questionamento sobre a constitucionalidade do ato, como também municiando o administrador de elementos técnicos relevantes no eventual exame judicial dessas políticas públicas.

Dessa forma, no que diz respeito às políticas públicas idealizadas pela União aplicáveis por similitude aos demais entes federativos, a Advocacia Pública deve desempenhar suas funções de consultoria e assessoramento jurídicos à administração consciente da importância e do impacto da atividade na qualidade das políticas públicas formuladas e implementadas pelo Estado. Os advogados públicos e demais servidores técnico-administrativos, não sendo diretamente ligados aos aspectos políticos, possuem preparação e especialização técnica e profissional necessária à implementação impessoal dessas decisões e ao assessoramento técnico-burocrático essencial à sua formulação.

Por fim, torna-se imperioso destacar que a legislação direciona-se no sentido de estimular à solução pacífica de conflitos. Na busca da consensualidade, além da arbitragem (Lei $\mathrm{n}^{\circ}$ 9.307/96), o Código de Processo Civil (CPC/15) apresenta algumas práticas cooperativas envolvendo o poder público, dentre as quais a criação, pelos entes públicos, de câmaras de mediação e conciliação. A utilização desses mecanismos de composição extrajudicial de conflitos, além de contribuir para a redução da litigiosidade, pode servir de ferramenta para que a Administração Pública, por meio da Advocacia Pública, retome o destino das políticas públicas, como protagonista.

\section{CONSIDERAÇÕES FINAIS}

Ante o exposto, com o referencial teórico e metodologia adotados, verificou-se que, no atual contexto, com o intuito de fornecer ao administrador público a segurança jurídica na tomada de decisões, a Advocacia Pública surge como coparticipe na defesa e implementação de políticas públicas. Inserta na CRFB/88 como função essencial à Justiça, com a finalidade de diretamente ou através de órgão vinculado, representar os respectivos entes federativos, judicial e extrajudicialmente, cabendo-lhe, ainda, as atividades de consultoria e assessoramento jurídico do Poder Executivo. 
Restou constatado que o papel da Advocacia Pública como verdadeira Advocacia de Estado, de forma a servir a sociedade, independente do governo - este momentâneo, aprimorando o controle preventivo da licitude dos atos administrativos e atuando, dentre outros, é de extrema importância na efetiva viabilização das políticas públicas nas respectivas áreas de abrangência: federal, estadual e municipal.

Em casos concretos, foi possível demonstrar como a atuação da Advocacia Pública tem sido imprescindível para concretizar diversas políticas públicas do Estado, que servem a toda à sociedade, especialmente nas áreas sociais: saúde, educação, previdência e assistência social, dentre outras.

Com a crescente judicialização das políticas públicas, conclui-se que a atuação da Advocacia Pública deve estar alicerçada entre a necessidade de oferecer ao ente representado os mecanismos jurídicos à satisfação das necessidades coletivas e, ao mesmo tempo, exercer papel preventivo para que direitos e garantias fundamentais dos cidadãos não sejam desrespeitados pelos diversos órgãos, respeitando-se os limites dos poderes que são outorgados aos advogados públicos para a defesa e concretização dos interesses estatais.

Nesse contexto, a utilização de meios alternativos de composição de conflitos pode servir de ferramenta para que a Administração Pública, através da Advocacia Pública, dentro da sua legítima parcela de corresponsabilidade política, retome o destino das políticas públicas, como protagonista.

Não resta dúvida de que atuando em parceria com os órgãos vinculados, construindo teses e viabilizando as políticas públicas mediante a formatação jurídica das ações da Administração, a Advocacia-Geral da União estará contribuindo decisivamente para o acesso ao direito e a realização da justiça.

Assim, queda-se importante e fundamental nas etapas de formulação e execução das políticas públicas as atividades de consultoria e assessoramento jurídicos, seja no esclarecimento dos vínculos jurídicos que delimitam a discricionariedade administrativa, seja no oferecimento de oportunidades para análise prévia das diversas possibilidades de escolhas disponíveis e os possíveis riscos e consequências jurídicas das decisões emanadas pelos administradores públicos.

\section{REFERÊNCIAS}


BRASIL. Supremo Tribunal Federal. ADI 1616. Disponível em: $<$ http://www.stf.jus.br/portal/jurisprudencia/pesquisarJurisprudencia.asp $>$ : Acesso em: 16 nov. 2018 .

Supremo Tribunal Federal. ADI 3916. Disponível em: < http://www.stf.jus.br/portal/jurisprudencia/pesquisarJurisprudencia.asp >: Acesso em: 16 nov. 2018.

Supremo Tribunal Federal. ADI 4249. Disponível em: < http://www.stf.jus.br/portal/jurisprudencia/pesquisarJurisprudencia.asp $>$ : Acesso em: 16 nov. 2018.

CURY, Tiago Gubert. Entre a judicialização e a juridicização da política: o espaço que cabe à Advocacia de Estado. Revista Brasileira de Advocacia Pública - RBAP, Belo Horizonte, ano 3, n. 4, jan./jun. 2017. Disponível em: $<$ http://www.bidforum.com.br/PDI0006.aspx?pdiCntd=247830>. Acesso em: 16 nov. 2018.

GUEDES, Jefferson Carús; HAUSCHILD, Mauro Luciano. Nos limites da história. A construção da Advocacia-Geral da União: livro comemorativo aos 15 anos. Brasília: UNIP: UNAFE, 2009.

GUIMARÃES, Guilherme F. A. Cintra. Advocacia de estado, administração pública e democracia: a função da consultoria jurídica na formulação e execução de políticas públicas. In: Democracia, Direito e Gestão Pública: textos para discussão. Samuel A. Antero e Valéria Alpino Bigonha Salgado (Orgs.). Fundação Instituto para o Fortalecimento das Capacidades Institucionais - IFCI/Agência Espanhola de Cooperação Internacional para o Desenvolvimento - AECID/Ministério do Planejamento, Orçamento e Gestão MPOG/Editora IABS, Brasília-DF, 2012. Disponível em $<$ http://www.planejamento.gov.br/assuntos/gestao-publica/programas-e-projetos-degestao/arquivos/vol_5_textos_para_discussao_ciclo_de_debates.pdf $>$. Acesso em: 16 nov. 2018.

KELSEN, Hans. Teoria pura do direito; tradução João Baptista Machado. 6. ed. São Paulo: Martins Fontes, 1999. Disponível em <https://portalconservador.com/livros/Hans-KelsenTeoria-Pura-do-Direito.pdf>. Acesso em: 16 nov. 2018.

KIRCH, César do Vale. A necessária participação da Advocacia-Geral da União no processo de políticas públicas. Jus Navigandi, Teresina, ano 7, n. 66, jun. 2003. Disponível em $<$ http://jus.com.br/revista/texto/4139>. Acesso em: 16 nov. 2018. 
LIMA, Flávia Danielle Santiago. Ativismo e autoconcentração no Supremo Tribunal Federal: uma proposta de delimitação do debate. 15/02/2013. 300f. Tese (Doutorado). UFPE. Recife, 2013.

MONTESQUIEU, Charles de Secondat, Baron de. O espírito das leis, Trad. Cristina Muracho. 2. ed. (1996), 2. triagem (2000). São Paulo: Martins Fontes, 1996.

MOREIRA NETO, Diogo de Figueiredo. As funções essenciais à justiça e as procuraturas constitucionais. Revista de Direito da Procuradoria Geral do Estado de São Paulo, n. 36, dez. 1991.

PEDONE, Luiz. Formulação, implementação e avaliação de políticas públicas. Brasília, FUNCEP, 1986, p. 11-12.

SILVA, José Afonso da. A advocacia pública e o estado democrático de direito. Revista de Direito Administrativo. v. 230 FGV. Rio de Janeiro, 2002.

VALENTE. Maria Jovita Wolney. Histórico e evolução da Advocacia-Geral da União. Brasília, AGU, 2013. Disponível em $<$ http://www.agu.gov.br/page/content/detail/id_conteudo/74710>. Acesso em: 16 nov. 2018.

\title{
THE ROLE OF FEDERAL PUBLIC ADVOCACY IN THE DESIGN AND IMPLEMENTATION OF PUBLIC POLICIES
}

\begin{abstract}
The study presented aims to demonstrate the importance of the actions of federal public advocacy, especially in the phases of conception and implementation of public policies. Initially we seek to address the historical background, composition and careers of the law-General of the Union. After, it seeks to analyze the constitutional and legal attributions of the institution and its position in the Federal constitution of 1988 as an essential function of justice. Deductive methodology is adopted, seeking elements in legislation, jurisprudence and doctrine, with critical-constructive analysis.
\end{abstract}

Keywords: Federal Public Advocacy. Essential function of justice. Historic. Composition and assignments. Action in the design and implementation of public policies. 